\title{
Psicanálise, Psicologia e Ciência: continuação de uma polêmica
}

\author{
Raul Albino Pacheco Filho \\ Pontifícia Universidade Católica de São Paulo
}

Em "Psicologia x Psicanálise: um ponto de vista lacaniano", texto publicado em Estudos de Psicologia, 1996, v. 1, n. 2, 287-298, argumenta-se que Psicanálise e Psicologia seriam disciplinas absolutamente distintas, em função de diferenças radicais de objeto de estudo e no posicionamento em relação à Ciência. A Psicologia aspiraria à cientificidade, restringir-se-ia ao estudo das formações imaginárias do Eu e direcionaria suas práticas à reprodução da ordem social. Já a Psicanálise não poderia ser incluída entre as ciências modernas, por não lidar com fatos objetivos nem observáveis; além disso, ela rejeitaria os objetivos da Psicologia de adequação e adaptação do $\mathrm{Eu}$ à realidade. $\mathrm{O}$ presente artigo apresenta o questionamento de elementos importantes dos argumentos e conclusões do texto citado. Rejeitam-se as idéias de que a Psicologia fundamentar-se-ia na concepção aristotélica do que seja a verdade do conhecimento e de que teria como vocação inescapável a reprodução da ordem social existente. Recordam-se as opiniões de Freud sobre a cientificidade da Psicanálise, assinalando-se a oposição entre seu ponto de vista e o do texto em exame. Questiona-se a concepção apresentada no texto do que seja replicabilidade em Ciência, argumentando-se que ela parece refletir uma posição empiricista e positivista radical do que seja Ciência.

Palavras-chave: Psicologia, Psicanálise, Filosofia da Ciência, Epistemologia da Psicologia, Epistemologia da Psicanálise. 
$\mathrm{E}$ ste texto nasceu de um convite a mim endereçado pelo editor de Estudos de Psicologia, para debater as idéias expressas em Psicologia x Psicanálise: um ponto de vista lacaniano (Kupfer, 1996). Ele deveria ter sido incluído no número anterior desta revista, juntamente com o artigo a ser comentado e com as análises de outros dois articulistas. Questões de ordem pessoal impediram-me de aprontá-lo a tempo e é por esta razão que só neste número ele pôde ser incluído.

Parece-me que o objetivo principal do referido artigo é argumentar que a Psicanálise "[...] não pode ser alinhada entre as Psicologias."(p. 287). E o centro das considerações concerne às diferenças entre "[...] a posição de ambas - Psicologia e Psicanálise - em relação à Ciência, o solo epistemológico sobre o qual se apoiam e seu objeto privilegiado de reflexão"(p. 287), que a autora busca evidenciar.

Em seu ponto de vista, o "ideal científico de objetividade" da Psicologia exigiria "[...] que o conhecimento daí advindo possa ser considerado verdadeiro. Desde Aristóteles, assim se define o conhecimento verdadeiro: é aquele que provém da adequação entre a coisa (o objeto) e a razão (ou a inteligência, o pensamento, vale dizer, o sujeito)" (p. 289). Consequientemente, todas as psicologias - as comportamentais e não comportamentais, a Psicologia Genética, a Psicologia Experimental, a Psicologia da Gestalt, a Psicologia Social e a Psicologia Clínica - teriam como "estrutura mínima organizadora" essa busca de correspondência entre "[...] o objeto (percepto), a estrutura de pensamento do sujeito que percebe (percipiens) e a representação perceptiva (perceptum)." (Jerusalinsky, apud Kupfer, 1996, p. 289). Este último argumento, a autora busca em um seminário proferido pelo autor citado, para fundamentar as suas próprias conclusões.

Dessa procura de toda psicologia moderna - "uma 'encomenda' que o empirismo lhe endereçou" - só poderia decorrer "o ideal de adaptação". Disso não escapariam as psicologias comportamentais nem as não estritamente comportamentais, sendo que nestas últimas "[...] o Eu ocupa[ria] necessariamente um lugar central” (p. 290). Esse Eu esforçar-se-ia por 
“[...] conformar-se a aquilo que Jurandir Freire Costa (1986) chamou de Tipo Psicológico Ordinário" (Kupfer, p. 291), estando as psicologias "[...] ocupadas em definir suas funções, seu modo de funcionamento, e sua relação com o campo social" (p. 291), de modo a torná-lo "[...] adequado, adaptado, conforme aos ideais sociais postos de antemão" (p. 291): um reprodutor da ordem social. E, fazendo suas as palavras de Jacques Lacan, a autora afirma que "[...] tanto a Psicologia dos processos do Eu como a Psicologia Clínica centram seus princípios e práticas nas formações imaginárias do Eu." (p. 292).

Analisando a posição da Psicanálise em relação à Ciência, a autora busca em textos de Paul Ricoeur argumentos para tentar demonstrar que "a Psicanálise não pode[ria] ser incluída entre as Ciências Modernas - e isto nem sequer é desejável." (Kupfer, p. 292). Em contraste com a Psicologia, que seria "[...] uma ciência da observação, que versa[ria] sobre os fatos da conduta" (Ricoeur, apud Kupfer, 1996, p. 293), a Psicanálise seria uma "[...] ciência exegética, que versa[ria] sobre as relações de sentido entre os objetos substituídos e os objetos originários (e perdidos) da pulsão." (Ricoeur, apud Kupfer, 1996, p. 293). “[...] Desde o princípio [ela] não opera[ria] com fatos observáveis, mas com interpretações, com sentidos. Em uma palavra: com linguagem." (Kupfer, p. 293). Sendo assim, não poderia aspirar ao ideal de cientificidade, porque uma interpretação, ainda alinhando-se com Ricoeur, "[...] não pode (nem deve) ter nenhuma objetividade.” (p. 293). Ao contrário, uma interpretação "[...] 'adere[ria] à relação singular do analista com o analisando', e não pode[ria] ser submetida, entre outras coisas, a uma verificação de seu acerto através da avaliação de juizes independentes. Deste ponto de vista, a interpretação é[seria] uma construção que se tece na e pela transferência, o que a torna[ria] única e irrepetível." (p. 293).

Em seu trabalho no campo da palavra, o foco de interesse da Psicanálise recairia sobre as "[...] formações que são disruptivas, não adaptativas, que estão mais do lado do horror do que do lado do funcionamento egóico. Um psicanalista 
poderá ver nelas a presença de algo que não coincide com nenhum dos objetos de nenhuma Psicologia. Não procurará definir aí um comportamento desviante, não buscará a relação de adequação ou de inadequação entre uma percepção do Eu e a realidade." (Kupfer, p. 294). Conseqüentemente, o sujeito estudado pela Psicanálise não coincidiria com o Eu do sujeito e também não com o sujeito do cogito da filosofia cartesiana. "Esse sujeito [da Psicanálise] não responde[ria] à lógica ou ao tempo da consciência, não se faz[ria] regular pelo princípio do prazer ou da realidade, e além do mais, não precisa[ria] estar por ela regulado.” (p. 294). E a Psicanálise buscaria o dizer desse sujeito, ao invés de procurar compreendê-lo e adaptá-lo; e, nisso, estaria longe da Psicologia e do Empirismo.

Acreditando ser este um resumo correto das posições centrais da autora no artigo, procurarei agora explicitar algumas das minhas discordâncias. A primeira delas relaciona-se com o fato de, em seu afã por distinguir Psicanálise de Psicologia, a autora terminar por tratar como homogêneas, de modo simplificado e incorreto, escolas e abordagens que apresentam diferenças radicais: tanto em suas proposições teóricas quanto em seus métodos de investigação, concepções filosóficas e pressupostos epistemológicos. É inviável, por exemplo, aceitar que a concepção de Aristóteles, do que seja a verdade do conhecimento, possa ser estendida a todos os sistemas da Psicologia. Em um artigo de 1931 - "O conflito entre os modos de pensamento aristotélico e galileano na psicologia contemporânea" - Kurt Lewin procurou mostrar como o corte epistemológico realizado pela física moderna foi constituído exatamente pelo afastamento do modo aristotélico de pensar e de elaborar conceitos. E recomendou, já naquela época, providência análoga à Psicologia, traçando o seu programa para que ela pudesse avançar na direção do que ele denominava modo galileano de pensamento e produção de conhecimento. Outros autores da Psicologia também exprimiram pontos de vista análogos sobre as deficiências do modo aristotélico de produção de conhecimento, podendo ser consultados, por 
exemplo, Köhler (1947) e Brown (1935), além de um outro texto do próprio Lewin (1936).

A impropriedade da idéia de que todas as psicologias teriam como "estrutura mínima organizadora" a busca de correspondência entre o objeto (percepto), a estrutura de pensamento do sujeito que percebe (percipiens) e a representação perceptiva (perceptum) fica absolutamente evidente quando se considera que a questão das relações envolvendo acontecimentos no mundo físico, corpo e psique sempre constituiu área das mais disputadas controvérsias no interior do campo da Psicologia. Posições monistas, dualistas, interacionistas ou a favor de um paralelismo psicofísico são exemplos de soluções distintas que têm sido propostas pelas diferentes escolas da Psicologia, ao longo do tempo. Ressalte-se, além disso, que a suposição de que a verdade do conhecimento repousa sobre a base de uma pretensa coincidência, entre o objeto no mundo exterior e a representação que dele oferece a Ciência, parece ser uma crença que têm angariado pouco prestígio na Psicologia e, de modo mais amplo, em todas as disciplinas científicas. Mesmo entre autores psicólogos cuja produção é habitualmente incluída entre as correntes mais afinadas com o Positivismo e o Empirismo - as chamadas teorias estímuloresposta - como é o caso de Edwin Guthrie, encontramos a idéia da Ciência como uma atividade lingüística e a concepção de que tanto os fatos como as teorias são verbais. ${ }^{1}$

Aliás, basta pensar-se na conceptualização de mundo oferecida pela própria Física, para se constatar o equívoco da idéia de que a Ciência visaria essa correspondência entre objeto, pensamento e representação perceptiva. $\mathrm{O}$ mundo que nos é apresentado por nossas representações perceptivas é feito de objetos, texturas, cores, cheiros e tantas outras coisas radicalmente diferentes das que habitam o mundo que nos é apresentado pela Física. Neste último, não existem os objetos familiares à nossa percepção e sim bizarras nuvens de elétrons de dimensões e massa desprezíveis, deslocando-se ao redor de prótons microscópicos, em vazios imensos; em lugar das nossas conhecidas cores, só podemos encontrar diferenças em comprimentos de ondas eletromagnéticas; ao invés de odo- 
res, apenas evaporações de sólidos e suspensões de partículas no ar. O contraste é óbvio e profundo e mostra o erro de se pretender que a Psicologia, ou a Física, ou qualquer disciplina científica, de um modo geral, tenham como objetivo a correspondência entre suas proposições e as representações perceptuais.

A inconveniência dessa proposta da autora, de aceitar "estruturas mínimas organizadoras" generalizáveis para todas as psicologias, ou até mesmo para todas as ciências, fica absolutamente transparente quando se retomam todas as controvérsias que vêm opondo epistemólogos, historiadores, sociólogos e filósofos da Ciência, ao longo do tempo, acerca de quais são os traços comuns das produções ditas científicas. Teriam os teóricos do Círculo de Viena a mesma opinião que Gaston Bachelard ? E Karl Popper, concordaria com Thomas Kuhn a respeito desse assunto ? E Imre Lakatos, o que diria da opinião destes últimos e da posição assumida pela autora ? ${ }^{2}$ Não consigo imaginar nada nem de perto parecido com um consenso, em relação a essa "fórmula mínima" proposta.

Um outro exemplo de afirmação generalizadora encontrada no artigo em exame, que não se harmoniza com os acontecimentos no campo da Psicologia, é a alegação de que toda a psicologia moderna estaria marcada pelo ideal de adaptação do indivíduo à ordem social e, conseqüentemente, limitada, em seus princípios e práticas, às formações imaginárias do Eu. Se é verdade que todas as produções culturais no Ocidente têm sofrido a influência ideológica do contexto capitalista, não se pode negar o fato de que, no caso da Psicologia, uma autocrítica cada vez mais vigorosa iniciou-se há pelo menos duas décadas; e isso, principalmente na América Latina. Lane (1985) descreve o desenvolvimento desse movimento crítico a uma psicologia atrelada ideologicamente ao contexto político, social e cultural capitalista, já em meados da década de 70. Montero (1996, pp. 115-16) situa igualmente nessa época o desenvolvimento, na América Latina, de uma psicologia que estuda a própria ideologia e que tem, entre seus objetivos, tornar-se um agente ou catalisador de transformações sociais. E, no caso do Brasil, o próprio posicionamento 
das entidades representativas dos psicólogos mostra uma rejeição da postura de simples reprodução da ordem social vigente. A participação dos conselhos regionais e sindicatos de psicólogos nas lutas antimanicomiais, ou contra os massacres de populações de presídios, ou de participação em movimentos políticos populares, ou contra uma formação profissional do psicólogo especializada, fragmentada e de não conscientização dos mecanismos políticos, econômicos e sociais são todos exemplos dessa não resignação à função de manutenção do establishment social. ${ }^{3}$

É verdade que a existência dessas posições críticas mais avançadas não sugere que os psicólogos constituam uma categoria homogênea, maciçamente consciente da necessidade de se questionar a função social e política da sua atividade profissional. Não acredito que as coisas ocorram deste modo, infelizmente. Mas isso não autoriza argumentar, como o faz a autora, que o alinhamento com os valores e ideais do sistema e com a reprodução de tipos psicológicos ordinários seja uma vocação obrigatória da Psicologia. Essa é tão somente uma lamentável possibilidade, como, aliás, também o é no caso da própria Psicanálise: fato confirmado pela autora, ao lembrar a atuação da psicanálise do ego norte-americana. E isso deve servir como sinal de alerta: fazendo analogia com uma possível doença, inclino-me a pensar antes em medidas preventivas e profiláticas do que em lamentações sobre deformidades congênitas incuráveis.

A respeito da limitação da atuação da Psicologia às formações imaginárias do Eu, ela só é verdadeira se nos restringirmos ao período anterior à disseminação da influência da própria Psicanálise. Circunscrita aos fenômenos da consciência, de um lado, ou aos eventos comportamentais, de outro, a Psicologia não poderia oferecer explicações convincentes nem ao menos dos mais modestos acontecimentos humanos. Neste sentido, parece-me que Freud estava absolutamente correto ao afirmar, nas primeiras décadas do século, que "a psicologia barrara seu próprio acesso à região do id, insistindo num postulado que é bastante plausível mas insustentável: a saber, que todos os atos mentais são conscientes para nós - que ser 
consciente é o critério do que é normal, e que, se há processos em nosso cérebro que não são conscientes, não merecem ser chamados de atos mentais e não são de qualquer interesse para a psicologia." (Freud, 1926/1987d, p. 224) Também não vejo como fazer reparos à sua afirmação de que a Psicanálise foi "[...] a primeira [e, eu acredito, a melhor] tentativa de uma psicologia profunda". (Freud, 1919/1987b, p. 218) Ela ofereceu uma clara evidência da relevância do inconsciente e permitiu progressos formidáveis no conhecimento da construção do Eu, da importância da imagem do semelhante nesse processo e da relação essencialmente narcísica que o indivíduo desenvolve com o seu Eu. Porém, repetir a crítica de Freud à Psicologia, mais de setenta anos passados, requer manter os olhos cerrados para tudo o que foi desenvolvido ao longo desses anos. Desenvolvimentos esses, aliás, fertilizados pela própria interação com as contribuições da Psicanálise.

De modo algum pode-se dizer que, ainda hoje, a Psicologia, como um todo, permanece resistente à aceitação do inconsciente. Como não poderia deixar de ser, a introdução das idéias psicanalíticas marcou definitivamente o pensamento de quem se debruça sobre o estudo dos fenômenos psicológicos. É claro que cada escola ou abordagem tenta conceptualizar os eventos inconscientes no interior do seu quadro referencial teórico, o que se traduzirá em diferenças eventualmente substanciais na própria concepção do que sejam esses fenômenos. Mas, desde Freud, o Eu e a consciência definitivamente não desfrutam do mesmo prestígio e nem ocupam o mesmo lugar central em todas as explicações dos psicólogos.

O mais criticável nas proposições do artigo em exame é a ambigüidade subjacente à afirmação de que toda e qualquer psicologia deveria centrar seus princípios e práticas às formações imaginárias do $\mathrm{Eu}$ e de que os objetivos de suas atuações visariam à adaptação do indivíduo aos ideais sociais vigentes. Fica ambíguo se a autora está fazendo uma crítica ou uma prescrição à Psicologia. Pois, se é uma crítica, o esperado seria que se cobrasse, como fez Freud, uma correção dos rumos que a Psicologia tem assumido: que ela dirigisse sua atenção para os objetos mais apropriados, cuja relevância 
a Psicanálise teve o mérito de desvendar. Neste caso, a diferença de objetos entre Psicanálise e Psicologia seria decorrência de um erro programático desta última, passível [e merecedor] de correção. Não estaria autorizado distinguí-las, de modo definitivo, em função de pretensas diferenças inconciliáveis de objeto. Já no caso de estar sendo prescrito à Psicologia que se restrinja a esse objeto, a autora ficou devendo as razões de porque pensa ser desejável isto ocorrer deste modo. Será que ela conceptualizaria tal psicologia como uma disciplina relevante, independente da Psicanálise, com um domínio e um objeto adequados e distintos, em relação à validade dos quais a Psicanálise nada teria a obstar ? E com a qual a Psicanálise poderia até mesmo interagir de modo colaborativo, como sói acontecer entre ciências realmente autônomas ? Para mim, isso soaria estranho e equivocado.

Deixando de lado as análises do artigo sobre os objetos da Psicanálise e da Psicologia, quero agora examinar as proposições apresentadas sobre as relações entre essas duas disciplinas e a Ciência. E meu primeiro comentário tem como objetivo lembrar que a posição do próprio Freud era absolutamente oposta à de Ricoeur e à da autora. Em todas as inúmeras ocasiões em que se pronunciou sobre esse assunto, ao longo de sua extensa vida como profissional e pensador, exprimiu a mesma convicção de que a contribuição fundamental da Psicanálise fora o desenvolvimento de um método para se abordar cientificamente os fenômenos psíquicos. Conservou uma inabalável certeza, em toda a sua carreira intelectual, de que de nada valeriam a criatividade ou engenhosidade especulativa de suas formulações, não estivessem elas fundamentadas em sólidas bases científicas a respaldar o seu grau de veracidade. Exprimiu seu aborrecimento em relação a um artigo de Havelock Ellis, em uma determinada ocasião, por ele elogiar as suas qualidades artísticas. Classificou-o como "[...] uma forma altamente sublimada de resistência [...] a forma mais refinada e amistosa de resistência, chama-me de grande artista a fim de prejudicar a validade de nossas pretensões científicas." (Freud, apud Jones, 1961/1979, p. 587). Para ele, a Psicanálise teria obtido sucesso no empreendimento em que 
outras abordagens teriam fracassado: na constituição de uma psicologia verdadeiramente científica.

Enquanto que a psicologia da consciência nunca foi além das seqüências rompidas que eram obviamente dependentes de algo mais, a outra visão, que sustenta que o psíquico é inconsciente em si mesmo, capacitou a Psicologia a assumir seu lugar entre as ciência naturais como uma ciência. Os processos em que está interessada são, em si próprios, tão incognoscíveis quanto aqueles de que tratam as outras ciências, a Química ou a Física, por exemplo; mas é possível estabelecer as leis a que obedecem e seguir suas relações mútuas e interdependentes ininterruptas através de longos trechos - em resumo, chegar ao que é descrito como uma 'compreensão' do campo dos fenômenos naturais em apreço. Isto não pode ser efetuado sem estruturação de novas hipóteses e criação de novos conceitos, e estes não devem ser menosprezados como indício de embaraço de nossa parte, mas, pelo contrário, merecem ser apreciados como um enriquecimento da Ciência. (Freud, 1940/1987e, pp. 183-84).

Em relação à questão de se a Psicanálise seria ou não uma ciência amparada em observações, a opinião de Freud também manteve-se absolutamente consistente ao longo de sua vida. E, novamente, era oposta à da autora e de Ricoeur. Aliás, uma das críticas de que mais ele se ressentia era a acusação de que suas teorias não haviam sido extraídas da observação dos fatos:

Se pudéssemos, ao menos, levar os nossos opositores a compreender que todas as nossas conclusões são derivadas da experiência - experiência que, no que me toca, outros pesquisadores podem tentar interpretar de outra maneira - e que não surgiram da ponta dos nossos dedos ou foram concatenadas numa escrivaninha de escritório. Isso é o que realmente todos eles pensam, partindo da sua própria maneira de atuar. (Freud, carta a Pfister, apud Jones, 1961/1979, p. 466). 
Acreditava que o método psicanalítico permitira libertar a investigação dos fenômenos psíquicos do domínio exclusivo da Filosofia, fornecendo-lhe uma base sólida e científica de observações sobre o seu objeto de estudo:

A Psicanálise não é, como as filosofias, um sistema que par-
te de alguns conceitos básicos nitidamente definidos, procu-
rando apreender todo o universo com o auxílio deles, e, uma
vez completo, não possui mais lugar para novas descobertas
ou uma melhor compreensão. Pelo contrário, ela se atém aos
fatos de seu campo de estudo, procura resolver os proble-
mas imediatos da observação, sonda o caminho à frente com
o auxílio da experiência, acha-se sempre incompleta e sem-
pre pronta a corrigir ou a modificar suas teorias. Não há in-
congruência (não mais que no caso da física ou da química)
se a seus conceitos mais gerais falta clareza e seus postula-
dos são provisórios; ela deixa a definição mais precisa deles
aos resultados do trabalho futuro. (Freud, 1923/1987c, p. 29).

A contribuição metodológica da Psicanálise tinha para ele um valor inestimável, em função do seu apreço pela independência crítica frente ao pensamento tradicionalmente estabelecido. Era sobre a base da observação dos fatos que ele pretendia fundamentar os seus questionamentos e transformações das teorias vigentes, sendo por isso que, já em 1889, ao comentar suas divergências teóricas com Meynert (então, uma autoridade de reputação bem maior do que a de Freud), ele contestava:

[...] o respeito à grandeza, particularmente à grandeza intelectual, certamente está entre as melhores características da natureza humana. Mas é necessário ter o devido respeito pelos fatos. Não há porque recear dizer isso francamente, quando se trata de colocar de lado a dependência que se tinha em relação a uma autoridade, em favor da opinião própria, formada a partir do estudo dos fatos. (Freud, 1889/ 1987a, p. 112). 
Como se constata, em relação à questão da cientificidade da Psicanálise, a opinião freudiana era exatamente a oposta da apresentada no artigo em exame. Conseqüentemente, acho que a autora agiu acertadamente, ao adjetivar, no título do seu artigo, o ponto de vista que ela exprime em seu conteúdo: "um ponto de vista lacaniano". O criador da Psicanálise pensava bem diferente, a respeito do mesmo assunto. E o mesmo acontece com muitos outros psicanalistas, desde as primeiras adesões ao movimento de Freud, até os dias de hoje.

Não pretendo, porém, limitar-me a apontar as diferenças de opinião entre Freud e a autora. Acredito que o assunto é importante e continua mesmo a merecer discussões, razão pela qual também quero exprimir algumas das minhas próprias idéias a respeito. $\mathrm{E}$, sem dúvida, elas encontram-se bem mais próximas das de Freud (ainda que não sejam exatamente iguais) do que das formuladas no artigo.

A razão principal das minhas divergências em relação às opiniões da autora parece-me estar menos na conceptualização do que seja a Psicanálise e de como ela produz seu corpo teórico, do que na compreensão do que seja Ciência e de como se elabora o conhecimento científico. Tome-se, por exemplo, a afirmação de que, se a Psicanálise aspirasse ao estatuto científico, ficaria " $[. .$.$] legitimamente alinhada entre as Psico-$ logias, variando em relação a elas apenas pelo objeto de estudo - o inconsciente -, havendo porém a possibilidade de que ele seja capturado, medido, verificado pelo método experimental." (Kupfer, 1996, p. 292) Essa assertiva deriva-se, a meu ver, de uma compreensão incorreta do que sejam as maneiras científicas de se construir conhecimento científico. Se o método experimental fosse condição indispensável para a elaboração de teorias, não apenas a Psicanálise, mas também a Psicologia, a Arqueologia, a Biologia ...etc..., a Astronomia e boa parte da própria Física estariam inviabilizadas em suas pretensões à cientificidade.

No caso da Psicologia, por exemplo, a maior parcela dos fenômenos relevantes não poderia ser investigada, por razões de ordem ética que impedem submeter seres humanos a determinadas condições de experimentação. Em outras disci- 
plinas, como é o caso da Astronomia e da Arqueologia, deixando-se de lado as questões de ordem ética (que, diga-se de passagem, também aqui não são irrelevantes), testes experimentais das teorias não são factíveis na maioria das vezes. As elaborações e verificações das teorias devem ser realizadas exclusivamente com dados originados de observações não experimentais e, aliás, em boa parte das vezes realizadas em circunstâncias assistemáticas ou casuais. E mesmo nas disciplinas que se apoiam fortemente em experimentações, como é o caso da Biologia e da Física, corpos teóricos de extrema relevância e prestígio não se originaram em dados obtidos em contextos experimentais. Parece-me que é este o caso da Teoria da Evolução, na Biologia, e das especulações sobre as origens do universo, na Física.

Com base em exemplos como estes, sinto-me autorizado a afirmar que existe a possibilidade de se elaborar teorias científicas que não estejam amparadas em experimentos. A meu ver, a autora nega à Psicanálise a possibilidade do estatuto da cientificidade, por aderir a uma concepção empiricista, indutivista e positivista radical do que é Ciência: uma visão que, eu acredito, limita e distorce a realidade e o potencial do conhecimento científico. Isso fica ainda mais claro quando ela propõe que uma interpretação não possa (e não deva) ter nenhuma objetividade, por se basear nas condições únicas e irrepetíveis da transferência que se estabelece entre analista e analisando. Essa afirmação parece-me apoiar-se em uma apreciação incorreta do significado de replicabilidade em Ciência.

No sentido empregado no artigo, toda e qualquer replicação seria absolutamente impossível. A afirmação de que um fenômeno é replicável em Ciência não pode ser entendida como a exigência de que uma circunstância absolutamente idêntica à original possa ser obtida exatamente em todos os detalhes da primeira ocorrência. Neste sentido do termo, o objeto lançado por Galileu da torre de Pisa, para observação da queda livre dos corpos, também constituiu o registro de uma ocorrência única e irrepetível. Seria impossível obter-se um objeto exatamente igual, de mesma forma, massa e composição química, assim como uma ocasião de idênticas condições at- 
mosféricas - pressão do ar, velocidade dos ventos, temperatura etc. - para se arremessar um corpo com idêntica direção, sentido e aceleração escalar, de modo a se observar a sua trajetória. E nem por isso é inviável proceder-se a replicações que testem a sua teoria sobre a queda livre dos corpos.

O significado de replicabilidade implica tão somente na possibilidade de se repetir os parâmetros que se acredita serem relevantes para influenciar o fenômeno em estudo. E a suposição do que é ou não relevante já depende da concepção teórica que se tem do próprio fenômeno. Aqui, a Psicanálise não está sozinha. Não existe disciplina científica que opere com observações puras, isentas de interpretações teóricas. Estas, são a base para se planejar as próprias condições de observação dos fenômenos.

A questão é bastante complexa e não tenho a intenção de discuti-la neste curto espaço disponível. Arrolei alguns dos aspectos envolvidos apenas para justificar minha opinião de que a autora adotou, junto com Ricoeur, uma concepção simplista e incorreta do que seja replicação em Ciência. Desenvolver métodos e técnicas adequados à observação (e à replicação das observações) dos fenômenos, capazes de fundamentar a construção de teorias, está entre as mais difíceis e produtivas tarefas dos que se dedicam à atividade de investigação. E, na minha opinião, o método psicanalítico criado por Freud deve ser entendido como uma das mais engenhosas criações desta natureza. Uma contribuição talvez até mais importante do que o não pouco valioso legado de suas teorias.

Se é verdade que seria impossível a duplicação de uma relação única e particular entre um determinado analista e seu analisando, nem por isso é inviável que cada novo candidato a analista possa submeter-se a condições que lhe permitam observar os fenômenos que a Psicanálise permitiu desvendar: a relevância incontestável do inconsciente nos atos humanos, a invariável impossibilidade de se escapar aos percursos do Complexo de Édipo, a presença indefectível dos ruídos transferenciais nas relações entre os homens e os inúmeros outros eventos que a Psicanálise permitiu conhecer. E isso, seja para concordar com as teorias anteriormente propostas, 
seja para ampliá-las, corrigi-las, ou até mesmo reformulá-las, como, aliás, o próprio Freud fez diversas vezes.

Não pretendo, com estas opiniões, subestimar a dimensão das dificuldades inerentes ao estudo do Homem. Muito menos minimizar o duplo desafio enfrentado pela Psicanálise e pela Psicologia: $1^{\circ}$ ) construir, verificar e aperfeiçoar teorias, a partir de situações de observação que, desde o início, já levam a marca de interpretações baseadas na própria teoria que se quer avaliar (aqui, como já foi dito, sua tarefa não se distingue da de qualquer disciplina de investigação científica); $2^{\circ}$ ) tentar compreender um objeto que é ao mesmo tempo sujeito: que fala, interpreta e teoriza sobre si próprio, sobre os outros e sobre o mundo e que se transforma, se revela e se esconde a partir dessas interpretações que constrói (esta dificuldade, Psicanálise e Psicologia compartilham apenas com as demais ciências do Homem). Mas ainda que as dimensões da tarefa sejam gigantescas, maior ainda é a importância de que continue a ser realizada; e da maneira apropriada.

Os argumentos da autora sobre a absoluta inviabilidade de qualquer conhecimento objetivo sobre o Homem não foram capazes de me convencer. Além das impropriedades que procurei pôr em evidência, sua pretensão parece-me refutada pela própria existência concreta do método psicanalítico e das teorias que ele tem possibilitado formular. Essas teorias parecem-me ser elaboradas de modo distinto dos que caracterizam as produções da Arte ou da Filosofia. E isso, sem qualquer intenção de subestimar a relevância incontestável dessas outras maneiras de se refletir sobre o mundo e sobre o Homem.

Uma última palavra precisa ser dita para esclarecer que o fato de eu não ter sido convencido da necessidade da Psicanálise renunciar ao estatuto de cientificidade não significa que eu acredite que esse estatuto esteja devidamente explicitado. Freud esforçou-se por demonstrá-lo, mas é óbvio que não logrou silenciar dúvidas e desconfianças, seja entre os adversários, seja entre os próprios discípulos da Psicanálise (isso per- 
mite que haja quem questione se psicanálise é um termo que fica mais corretamente enunciado no singular ou no plural). E isso demonstra que os estudos metodológicos e epistemológicos que visam mostrar como a Psicanálise elabora as suas teorias ainda não completaram a sua obra. Em minha opinião, urge prosseguí-los.

\begin{abstract}
Psychoanalysis, psychology and Science: continuation of a controverse.

In "Psychology x psychoanalysis: a lacanian viewpoint", article published in "Estudos de Psicologia", 1996, 2, 287298, the argument was that Psychoanalysis and Psychology would be totally distinct disciplines due to radical differences concerning the object of study and their positioning regarding Science. Psychology would aim at scientificity, restricting itself to the study of imaginary formations of the Ego and directing its practice to the reproduction of social order. Psychoanalysis cannot be included among modern sciences as it does not work with objective or observable facts; moreover, it would reject the Psychology objectives of adaptation of the Ego to reality. This text presents the questioning regarding the important elements of the argumentation and conclusions presented in that article. The idea that Psychology would rely upon the Aristotelian concept of what could be true knowledge and that it would have as unavoidable vocation to the reproduction of the existing social order are rejected. Freud's opinions about the scientificity of Psychoanalysis and the contradiction between his viewpoint and the one presented in the article are exposed. The concept of replicability in Science shown in the article is questioned based on arguments that it seems to reflect a positivist empirical position of what Science can be.

Key-words: Psychology, Psychoanalysis, Philosophy of Science, Epistemology of Psychology, Epistemology of Psychoanalysis.
\end{abstract}




\section{Referências}

Bachelard, G. (1978) O novo espírito científico. In Gaston Bachelard. São Paulo: Abril Cultural (Obra original publicada em 1934).

Brown, J. F. (1935). Towards a theory of social dynamics. Journal of Social Psychology, 6, 182-213.

Conselho Regional de Psicologia da $6^{\text {a }}$ Região (1994). Uma profissão chamada Psicologia (CRP-06, 20 anos). São Paulo: Autor.

Costa, J. F. (1986). Saúde mental, produto da educação? In Violência e psicanálise ( $2^{\mathrm{a}}$. ed.). Rio de Janeiro: Graal.

Epstein, I. (1988). Revoluções Científicas. São Paulo: Ática.

Freud, S. (1987a). Resenha de 'Der Hypnotismus' de August Forel. In Edição Standard Brasileira das Obras Psicológicas Comple$\overline{\operatorname{tas}\left(2^{a}\right.}$. Ed., Vol. I) Rio de Janeiro: Imago. (Obra original publicada em 1889).

Freud, S. (1987b). Kell-e Az Egyetemen A Psychoanalyst Tanitani? In , Edição Standard Brasileira das Obras Psicológicas Comple$\overline{\operatorname{tas}\left(2^{\mathrm{a}}\right.}$. Ed., Vol. XVII) Rio de Janeiro: Imago. (Obra original publicada em 1919).

Freud, S. (1987c). Dois verbetes de enciclopédia. In Edição Standard Brasileira das Obras Psicológicas Completas (2 ${ }^{\mathrm{a}}$. Ed., Vol. XVIII) Rio de Janeiro: Imago. (Obra original publicada em 1923).

Freud, S. (1987d). A questão da análise leiga. In __, Edição Standard Brasileira das Obras Psicológicas Completas (2a . Ed., Vol. XX) Rio de Janeiro: Imago. (Obra original publicada em 1926).

Freud, S. (1987e). Esboço de Psicanálise. In __, Edição Standard Brasileira das Obras Psicológicas Completas (2a ${ }^{\mathrm{a}}$ Ed., Vol. XXIII) Rio de Janeiro: Imago. (Obra original publicada em 1940).

Hempel, C. (1965). Aspects of scientific explanation and other essays in the Philosophy of Science. Nova York: The Free Press.

Jones, E. (1979). Vida e obra de Sigmund Freud (edição resumida) (3 ${ }^{\mathrm{a}}$ ed.). Rio de Janeiro: Zahar. (Obra original publicada em 1961).

Köhler, W. (1947). Gestalt Psychology. Nova York: Liveright.

Kuhn, T. S. (1982). A estrutura das revoluções científicas. São Paulo: Perspectiva (Obra original publicada em 1962).

Kupfer, M. C. M. (1996). Psicologia x Psicanálise: um ponto de vista lacaniano. Estudos de Psicologia, 2, 287-298.

Lakatos, I., \& Musgrave, A. (1979). A crítica e o desenvolvimento do conhecimento. São Paulo: Cultrix/Universidade de São Paulo. (Obra original publicada em 1970).

Lane, S. T. M. (1985). A Psicologia Social e uma nova concepção do homem para a Psicologia. In S. R. M. Lane \& W. Codo (Orgs.), Psicologia Social - O homem em movimento ( $3^{\mathrm{a}}$ ed.). São Paulo: Brasiliense. 
Lewin, K. (1931). The conflict between Aristotelian and Galileian modes of thought in contemporary psychology. Journal of Gen. Psychol., 5, 141-177.

Lewin, K. (1936). Principles of topological psychology. Nova York: McGraw-Hill.

Marx, M. H., \& Hillix, W. A. (1974). Sistemas e teorias em Psicologia. São Paulo: Cultrix (Tradução da $2^{\mathrm{a}}$ edição de 1963)

Montero, M. (1996). Paradigmas, corrientes y tendencias de la psicologia social finisecular. Psicologia e Sociedade, 8(1), 102-119.

Popper, K. (1963). Conjectures and refutations. Londres: Routledge \& Kegan Paul.

\section{Notas}

${ }^{1}$ Veja-se Marx e Hillix (1963/1974), pp. 17-18, para uma discussão a esse respeito.

2 Para uma análise das posições destes autores, vejam-se as seguintes obras: Hempel (1965), Bachelard (1934/1978), Popper (1963), Kuhn (1962/1982), Lakatos e Musgrave (1970/1979) e Epstein (1988).

3 Veja-se, por exemplo, Conselho Regional de Psicologia da $6^{\mathrm{a}}$ Região (1994).

Raul Albino Pacheco Filho é professor do Programa de Estudos Pós-Graduados em Psicologia Social e da Faculdade de Psicologia da PUC-SP. Doutor em Psicologia pela Universidade de São Paulo. Endereço para correspondência: Programa de Estudos Pós-Graduados em Psicologia Social (PUC-SP), Rua Ministro Godói, 969, $4^{\circ}$ andar, sala 415, CEP: 05015-000, São Paulo (SP), fonelfax: (011) 873-2385. 